Janja Vuga, Katarina Rajh, Gašper Kavšek,

Katja Cimermančič, Rafaela Križman, Urška Učakar

\title{
SOCIALNA, INSTITUCIONALNA IN ORGANIZACIJSKA PODPORA V POHLEPNIH INSTITUCIJAH: ZADOVOLJSTVO SLOVENSKIH VOJAŠKIH DRUŽIN
}

\section{SOCIAL, INSTITUTIONAL AND ORGANISATIONAL SUPPORT IN GREEDY INSTITUTIONS: SATISFACTION OF SLOVENIAN MILITARY FAMILIES}

Povzetek Coser je vojaške organizacije in družino opredelil kot dve pohlepni instituciji, katerih tekmovanje za posameznikov čas lahko vodi v konflikt med delom in družino. Za uspešnejše usklajevanje so na voljo različne oblike podpore. Na podlagi veljavne teorije smo v članku izpostavili tri tipe podpore: socialno, institucionalno in organizacijsko. Zadovoljstvo z naštetimi tipi smo preverjali v 33 slovenskih vojaških družinah, med katerimi smo ugotavljali tudi to, koliko je Slovenska vojska med vojaškimi družinami razumljena kot pohlepna institucija. Analiza intervjujev kaže, da slovenske vojaške družine sprejemajo vojaški način življenja, ki zahteva pogoste in dolgotrajne odsotnosti, vendar pa partnerji/-ke velikokrat občutijo pohlepnost vojaške organizacije, ki večino bremena skrbi za otroke in gospodinjstvo, posebej v času napotitve na MOM, prelaga nanje. Vojaške družine posebno med daljšo odsotnostjo pripadnika/-ce kot primarni vir podpore dojemajo socialno okolje, pri čemer se pokaže pomen razširjene družine. Hkrati pa izpostavljajo nekatere zaželene oblike institucionalne podpore, na primer sistem hitrega obveščanja o dogajanju v MOM. Pozitivno je bil ocenjen dostop do interneta, ki omogoča komunikacijo s partnerji/-kami in otroki. Kot kaže, prav to zmanjšuje stres in odtujenost ob odsotnosti enega od staršev.

Ključne Socialna podpora, institucionalna podpora, organizacijska podpora, vojaške besede družine, pohlepne institucije.

Abstract Coser defined military organization and family as two greedy institutions where competition for individuals' rank can lead to a conflict between work and family. However, various forms of support are available to provide for a successful coordination of these two. On the basis of the existing theories, the paper defines three types of support: social, institutional and organizational. Satisfaction with these three types of support has been examined in 33 Slovenian military families. In this respect, we also tried to determine the extent to which the Slovenian Armed Forces is perceived 
by military families as a greedy institution. The analysis of the interviews shows that Slovenian military families accept the military way of life, which requires frequent and lengthy absences. Partners, however, often experience the greedy nature of a military organization, which burdens them with a great deal of care for children and household, especially during deployments. Especially during prolonged absence of their members, military families perceive social environment as a primary source of support. In this context, the importance of the extended family comes to forefront. At the same time, they point to some of the desired forms of institutional support, such as Rapid Alert System reporting on the developments in international missions and operation. They have positively evaluated Internet access, which enables communication with partners and children. It seems that the latter reduces stress and alienation in the absence of one parent.

Key words Social support, institutional support, organizational support, military families, greedy institutions.

Uvod Plačano delo je pomemben del posameznikovega življenja, saj zagotavlja finančno in materialno neodvisnost, pomembno vpliva na posameznikovo samozavest ter posledično pripomore h kakovostnejšemu življenju. Za doseganje slednjega pa je pomembno usklajevanje časa in energije med plačanim delom in družino.

Že leta 1956 je Whyte (v Orthner, Bowen \& Beare, 1990) predstavil koncept intenzivne prepletenosti zasebnega življenja delavcev z njihovim plačanim delom, ki se $\mathrm{v}$ angleščini imenuje organization man. Pri tem konceptu, ki se je začel razvijati po industrijski revoluciji, gre za popolno predanost delavcev organizaciji, v kateri so zaposleni (Whyte, 1956). Leta 1989 sta Bowen in Orthner (1989) koncept razumevanja družine v podporni funkciji potreb organizacije poimenovala organization family. Sodobno delovno okolje od zaposlenih vedno bolj zahteva pripadnost in predanost, čemur so namenjene različne oblike tehnik krepitve delovnih skupin, fleksibilnost dela itn., kar pa zmanjšuje čas, ki ga posameznik lahko nameni družini oziroma zasebnemu življenju (Crompton, 2006). Pri tem Crompton (2006) posebej poudarja vlogo žensk, ki so zaradi tradicionalnega razumevanja svoje vloge večkrat prisiljene podrejati svoje plačano delo (oziroma kariero) plačanemu delu partnerja in prevzemati večji del neplačanega dela, ki izvira iz družinskega okolja (vzgoja otroka, skrb za gospodinjstvo, skrb za starejše družinske člane ipd.) (Kanjuo Mrčela, 2007, str. 13-22).

Usklajevanje obveznosti plačanega dela in pričakovanj družine je vse težje (Sachau in drugi, 2012, str. 63), zaradi česar raziskovalci po vsem svetu preučujejo odnos med obema. Družina je namreč ključnega pomena tako za posameznika kot za družbo in zato velik delež odnosov znotraj posameznikovega osebnega omrežja predstavljajo prav odnosi znotraj družine (Vuga in Juvan, 2011, str. 91). Zahteve družinskih članov in organizacije med seboj niso vedno usklajene, kar potencialno vodi v konflikt med obema (Heilmann in drugi, 2009, str. 86). 
V zadnjih 22 letih so bile družine pripadnikov in pripadnic Slovenske vojske (SV) preučevane predvsem skozi prizmo pripadnikov/-ic, redko pa so bile vključene v raziskavo na način, ko bi lahko izrazili svoja lastna stališča. Opravljena raziskava je lahko razumljena kot spodbuda za nadaljnje raziskovanje. Namen članka je analizirati, kako pripadniki SV in njihovi družinski člani usklajujejo pričakovanja družine in zahteve vojaške organizacije ter kakšno vrsto podpore imajo. Izhajajoč iz različnih konceptov podpore in oblik podpore, predpisanih z nacionalno zakonodajo, ter izhajajoč iz koncepta pohlepnih institucij smo sledili naslednjim ciljem: 1) preučiti percepcijo pohlepnosti vojaške organizacije med slovenskimi vojaškimi družinami; 2) ugotoviti, kakšne oblike podpore (organizacijska, institucionalna, socialna) vojaške družine že imajo, predvsem v času mednarodnih operacij in misij (MOM); 3) kolikšno je zadovoljstvo vojaških družin s posameznim tipom podpore.

\section{KONFLIKT MED DELOM IN DRUŽINO V POHLEPNIH INSTITUCIJAH}

Konflikt med delom in družino se lahko razvije v dve smeri, in sicer konflikt, ki je usmerjen z dela na družino ali konflikt z družine na delo. Pri prvem se zaradi delovnih obveznosti razvije razdor znotraj družinskega okolja, pri drugem pa se razvije razdor znotraj delovnega okolja zaradi zahtev družine (Sachau in drugi, 2012, str. 63). Tisti posamezniki, ki doživljajo več konfliktov med delom in družino, so manj zadovoljni z delom, življenjem, zakonsko zvezo ter družino (Heilmann in drugi, 2009, str. 86; Durand v Sachau in drugi, 2012, str. 63). Gledano z vidika družine pa lahko nerazrešeni problemi ovirajo opravljanje vsakdanjih družinskih obveznosti (Juvan in Jelušič, 2007, str. 555). Konflikt med delom in družino povzroči tudi pomanjkanje osebnih virov, kot sta na primer čas in energija. Poleg tega zahteve ene institucije največkrat onemogočajo zahteve druge ter posebna zahtevana vedenja ene institucije onemogočajo izpolnitev vloge v drugi (Heilmann in drugi, 2009, str. 87). Usklajevanje delovnih in družinskih obveznosti je torej že samo po sebi zahtevno, a posebnosti in zahteve delovnega okolja so tiste, ki to usklajevanje še bolj otežijo (Vuga in Juvan, 2011, str. 92).

Vojaška organizacija je moško naravnana in s poudarkom na učinkovitosti, hierarhiji, prevladi in nadzorovanju čustev ter moči. Te vrednote pa niso vedno združljive z vrednotami, zaželenimi v družini, zaradi česar je lahko vojaško življenje za družine že samo po sebi problematično (Juvan in Jelušič, 2007, str. 557). Dosedanje ugotovitve kažejo, da vojaška organizacija s svojimi zahtevami bolj pritiska na družino kot družina na vojaško organizacijo (Vuga in Juvan, 2011).

\section{POHLEPNE INSTITUCIJE}

Koncept pohlepnih institucij je podrobneje opredelil Lewis A. Coser (1974, str. 4), ki pravi, da pohlepna institucija od svojih pripadnikov zahteva popolno ter izključno zvestobo, pri čemer si želi podrediti tudi posameznikovo osebnost. Coser (1974) je opredelil srednjeveško družino in vojaško organizacijo kot pohlepni instituciji, 
medtem ko je sodobna družina pohlepna predvsem do žensk, torej žena in mater (Coser, 1974, str. 89-90). Podobno ugotavlja tudi Segal (1986), ki je pohlepnost obeh institucij preverjala na primeru oboroženih sil ZDA in ugotovila, da sodobna družina in vojaška organizacija še vedno precej ustrezata Coserjevi definiciji ter sta opredeljeni kot pohlepni instituciji. Obema institucijama je skupen koncept preživetja, ki izhaja iz zvestobe njunih članov (Soeters in drugi, 2003, str. 237). Treba pa je upoštevati, da se raven zahtev obeh institucij spreminja glede na situacijo in življenjske okoliščine. Družina je veliko zahtevnejša in bolj pohlepna do svojih članov, ko gre za mladoporočence, družine z majhnimi otroki ali družine z otroki s posebnimi potrebami (Coser, 1974; Segal, 1986), medtem ko vojaška organizacija postavlja do svojih članov višje zahteve $\mathrm{v}$ času dolgotrajnih terenskih usposabljanj ter napotitev na MOM (Juvan in Jelušič, 2007).

Pohlepna narava institucije se kaže tudi v tem, da je delovanje takšne institucije odvisno od popolne zvestobe njenih članov. Pohlepne institucije se od totalnih razlikujejo po načinu podrejanja, pri čemer pri prvih podreditev temelji na prostovoljni odločitvi in institucionalni pripadnosti, pri drugih pa na prisili. Vsaka institucija svojim pripadnikom nalaga določena pričakovanja in zahteve. Vojaška organizacija pa je v svojih zahtevah do svojih pripadnikov specifična, kar posredno vpliva tudi na družinske člane in osebno okolje pripadnika (Vuga in Juvan, 2011, str. 91; Blanchard, 2012, str. 84). Zahteve vojaške organizacije, ki jo kot delovno organizacijo ločujejo od drugih takšnih organizacij, so med drugim nereden delovni čas, nepredvidljivost delovnih nalog, dolgotrajna odsotnost, pogoste selitve (MacDermid Wadsworth in Southwell, 2011, str. 170; Vuga in Juvan, 2011, str. 91; Blanchard, 2012, str. 84). Pravzaprav je lahko to, kako močno določene zahteve prevladujejo v življenju družine, ključna razlika med vojaško organizacijo in drugimi organizacijami (Blanchard, 2012, str. 84).

Verjetno največja posebnost vojaške organizacije pa je koncept neomejene svobode, za katerega Martin in McClure (2000, str. 16) pravita, da od pripadnikov oboroženih sil v določeni situaciji zahteva pripravljenost na žrtvovanje svojega življenja. Takšna nevarnost, da je posameznik lahko ubit ali ranjen, pa ni navzoča le v vojnem stanju, ampak tudi na usposabljanju ali na vojaških vajah in pri opravljanju vsakdanjega dela (Juvan in Jelušič, 2007, str. 556). Segal trdi, da je s tem izražena najvišja stopnja pohlepnosti vojaške organizacije (Segal, 1986, str. 16).

Družina od svojih pripadnikov podobno kot vojaška organizacija pričakuje čas in zvestobo ter jim nalaga neke zahteve (Soeters in drugi, 2003, str. 237). Od družinskih članov se pričakuje, da so svoji družini čustveno predani in da izpolnjujejo svojo vlogo znotraj družine. Pričakuje se tudi identificiranje z družino in zadostno izražanje ljubezni (Vuga in Juvan, 2011, str. 91). Družina in vojaška organizacija kot dve med seboj konkurenčni pohlepni instituciji torej tekmujeta za čas, predanost, zvestobo, čustva, energijo itn. svojih članov, kar lahko vodi v konflikt med obema institucijama. 
Za zmanjšanje konflikta med plačanim delom in družino je zelo pomembna podpora. Pripadnik vojaške organizacije in njegova družina se zaradi značilnosti dela v vojaški organizaciji pogosto znajdeta v situacijah, v katerih potrebujeta pomoč in podporo. Na podlagi te teorije tipe podpore delimo na organizacijsko, institucionalno in socialno podporo.

\section{TIPOLOGIJA PODPORE}

\subsection{Organizacijska podpora}

V sklop organizacijske podpore prištevamo tiste elemente, ki izhajajo iz vojaške organizacije in so namenjeni pripadnikom SV. Mednje uvrščamo nekatere ugodnosti (na primer možnost dela na domu, fleksibilnost delovnega urnika), socialno in delovno zakonodajo ter določbe, ki kakor koli vplivajo na posameznega pripadnika SV. Z organizacijsko podporo so se ukvarjali številni avtorji (Eisenberger, 1986; Rhoades in Eisenberger, 2002; Lapiere in drugi, 2008), ki organizacijsko podporo oziroma zaznano organizacijsko podporo opredeljujejo kot splošno prepričanje zaposlenega, da delovna organizacija ceni njegov prispevek in skrbi za njegovo blagostanje. Organizacijska podpora praviloma vodi k boljšemu počutju, vzajemnemu zaupanju med organizacijo in pripadnikom, boljšim delovnim rezultatom, identifikaciji z organizacijo ter občutku dolgotrajne zaveze (Sachau in drugi, 2011, str. 65). Organizacijska zavezanost vojakov je večja, ko vojaška organizacija omogoča več podpore (Bourg in Segal, 1999, str. 648). Organizacijska podpora, ki je namenjena pripadnikom, je torej sestavljena iz uradne, zakonsko predpisane, podpore ter podpore nadrejenih in zaposlenih.

Za našo analizo smo širok pojem organizacijske podpore, kot so jo definirali nekateri zgoraj omenjeni avtorji, zožili. Pri tem smo kot organizacijsko podporo opredelili aktivnosti, ki jih SV izvaja zaradi zagotavljanja z zakonom določenih pravic (na primer pravica do skrajšanega delovnega časa do otrokovega tretjega leta starosti) in dodatnih ugodnosti, ki pozitivno vplivajo na učinkovitost zaposlenih (na primer fleksibilnost delovnega urnika). Organizacijska podpora je usmerjena na zaposlene v SV. Aktivnosti, ki so namenjene tako pripadnikom in pripadnicam kot tudi njihovim družinam in primarnemu socialnemu okolju, pa smo opredelili kot institucionalno podporo. V SV je zakonsko zagotovljena podpora, ki naj bi povečala motivacijo in učinkovitost pripadnikov, vsebovana v določilih Zakona o službi v SV. Zakon o službi v Slovenski vojski $(Z S S l o V)^{1}$ določa, da imajo pripadniki zaradi posebnih obremenitev in odgovornosti pri svojem delu pravico do celostne skrbi, ki je natančno določena v sedmem poglavju.

Iz sklopa celostne skrbi za pripadnike SV, ki je sicer precej obsežna, so za organizacijsko podporo pomembna predvsem določila o napredovanju, delu na domu, nadurah in drugih oblikah, ki obravnavajo fleksibilnost dela in zadovoljstva pripadnika na delovnem mestu. Tovrstna vzajemna podpora je poleg formalne celostne

l Zakon o službi v Slovenski vojski (ZSSloV). Ur. l. RS 68/2007 (30. julij 2007). 
skrbi SV izjemnega pomena za dobro počutje pripadnikov, izboljšanje njihove delovne učinkovitosti ter identifikacijo z vojaško organizacijo in posamezno enoto.

Delovni čas pripadnikov je opredeljen v 53. členu in je odvisen od vrste, namena, obsega in zahtevnosti njihovih nalog ter je lahko neenakomerno razporejen. Delo na domu skladno s 54. členom lahko traja največ tri ure na dan. Po ukazu so lahko pripadniki napoteni na izobraževanje in usposabljanje, daljše od enega leta.

$\mathrm{Na}$ pripadnike SV se seveda nanaša tudi Zakon o delovnih razmerjih (ZDR-1)2. Zakon o delovnih razmerjih $\mathrm{v}$ členih od 187. do 193. namreč določa posebne ugodnosti za starše otrok, mlajših od treh let oziroma do šestega leta starosti najmlajšega otroka, če gre za družino z več otroki. Tovrstno posebno varstvo staršem (ne glede na spol) omogoča koriščenje starševskega dopusta ter posebne ugodnosti glede nočnega in nadurnega dela. Varstvo omogoča, da starši otrok, ki so mlajši od treh let, nadurno ali nočno delo opravljajo le, če se z njim predhodno strinjajo, in sicer s pisnim soglasjem. Podobno določilo se nanaša tudi na starše samohranilce otrok s posebnimi potrebami ali bolnega otroka do sedmih let. V praksi tovrstno varstvo torej pomeni, da se staršem otrok, mlajših od treh let, ni treba udeležiti usposabljanj v tujini, MOM ali opravljati nadur, čeprav gre na primer za pomoč pri zaščiti in reševanju poplavnih območij.

\subsection{Institucionalna podpora}

V vojaški organizaciji so pripadniki/-ce socializirani v duhu »najprej služba, potem zasebno življenje« (Martin in McClure, 2000). Zahteve vojaške organizacije naj bi torej presegle tako zahteve družine kot osebne zahteve pripadnika. Institucionalna podpora izhaja iz organizacije in je namenjena pripadnikom ter njihovim družinam. Nekatere vojaške organizacije že prek institucionalnega okvira skrbijo tudi za celovito oskrbo vojaške družine. Ameriška vojska je na primer odgovorna za dobrobit in psihološko zdravje pripadnikov ter njihovih družin, razvoj in izobraževanje otrok, karierne ter izobraževalne možnosti za partnerje in za skrb za otroke (SOMF, 2011). Tudi SV omogoča tako oskrbo, ki pa se seveda od ameriške razlikuje, saj je SV precej manjša od ameriške in ji je namenjen tudi manjši del državnega proračuna. SV je v skrbi za vojaške družine vključena že v 11. členu ZSSloV, ki določa, da mora nadrejeni skrbeti za čim boljše pogoje za delo ter pomagati družinam podrejenih, če te to želijo.

Celostna skrb SV obsega zdravstveno, psihološko, religiozno, duhovno in socialnovarstveno oskrbo, pravno pomoč in svetovanje ter športne dejavnosti in organizirano preživljanje prostega časa. Zakon o službi v SV določa tudi nekatere pravice, ki pripadniku pripadajo tudi po prenehanju dela v SV. 76. člen Zakona o službi v SV predvideva, da se določila o celostni skrbi za pripadnike SV smiselno navezujejo tudi na njihove družinske člane. Za institucionalno oporo je pomemben predvsem 80 . člen, ki vsebuje določila o socialnovarstveni oskrbi, ki je sestavljena iz svetovanja in

2 Zakon o delovnih razmerjih (ZDR-1). Ur. l. RS 21/2013 (13. marec 2013). 
pomoči pri reševanju stanovanjskega problema, svetovanja in pomoči pri zagotavljanju otroškega varstva, svetovanja pri zaposlitvi zakonca ter iz pomoči pri selitvah, če so te posledica prerazporeditve znotraj vojaške organizacije. Pomoč pripadnikom in njihovi družini je predvsem finančne narave. Pomemben je tudi 85. člen istega zakona o klubih in centrih za celostno skrb, ki vsebuje določila o klubskih prostorih in dejavnostih, ki so namenjeni pripadnikom ter družinskim članom.

\subsection{Socialna podpora}

Zadnji tip opore je socialna opora, ki je namenjena tako pripadniku SV kot njegovi družini in izhaja iz pripadnikovega ali pripadničinega primarnega socialnega okolja. V raziskavah, izvedenih na Obramboslovnem raziskovalnem centru, v obdobju od 2003 do 2008, so kot primarno socialno okolje definirani partnerji/-ke, starši in prijatelji (Vuga in Juvan 2011, str. 89 in 102). Socialno oporo težko merimo, njene oblike pa se od družine do družine razlikujejo. V Sloveniji je socialna opora postala posebej pomembna po letu 2003, ko je bila uvedena poklicna vojska, s čimer je naraslo število t. i. vojaških družin.

Kogovšek in drugi (2003, str. 184) oblike socialne podpore uvrščajo v štiri večje skupine: materialna, informacijska, emocionalna in socialna podpora. Socialno podporo je treba opazovati tudi z vidika sorodstvenih vezi, saj del odnosov znotraj posameznikovega osebnega omrežja predstavljajo odnosi znotraj družine (Kogovšek in drugi, 2003, str. 185). Družina je še vedno ključnega pomena tako za posameznika kot za družbo. »Družina je osnovna institucija zasebnega življenja, kjer se oblikuje večina za ljudi pomembnih družbenih odnosov.« (Dremelj, 2003, str. 152)

Socialna opora je razdeljena na dva dela. Prvi del je sestavljen iz podpore, ki jo družina in prijatelji pripadniku/-ci namenijo, ko se ta odloči za vstop v organizacijo. Drugi del, ki je pravzaprav še bolj bistven, je sestavljen iz podpore, ki jo družina in prijatelji namenijo pripadnikom/-cam med njihovim delom, napotitvami v MOM ter med urjenji. Tu je ključna predvsem vloga ožje družine, saj družinsko življenje na opravljanje službe vpliva tako v mirnem kot vojnem času (Schneider in drugi v Juvan in Jelušič, 2007, str. 554). Družine so pomemben vir zadovoljstva pripadnikov vojaške organizacije (Schneider in drugi v Juvan in Jelušič, 2007, str. 564) in v Sloveniji predstavljajo pomembno vrednoto (Vuga in Juvan, 2011, str. 97), zato je nujno, da so družine del oskrbe, ki jo zagotavlja organizacija pripadniku.

Poleg ožje družine, ki skrbi za usklajevanje obveznosti in močno psihološko podporo, so pomembni tudi prijatelji in širša družina. Ti poleg podpore in spodbujanja pripadnika v njegovem prostem času skrbijo tudi za pomoč družini pripadnika, ko je ta odsoten. Zaradi številnih družinskih obveznosti so partnerji in partnerke med odsotnostjo pripadnika večkrat preobremenjeni z obveznostmi, ki jih težko usklajujejo z lastnimi službenimi obveznostmi, zato je pomoč širše družine in prijateljev toliko pomembnejša. Bistveno je, da partnerke ali partnerji ne dojemajo pripadnikov ali pripadnic kot breme družini, saj le tako lahko podpirajo njegovo delo. Juvan in Jelušič (2007, str. 562-3) sta ugotovili, da v SV ne prihaja do intenzivnih konfliktov 
med SV in družino, saj v povprečju pripadniki/-ce menijo, da so njihove družine zadovoljne z vojaškim življenjem. Štiri leta pozneje pa sta Vuga in Juvan (2011) ugotovili, da vendarle prihaja do nekaterih napetosti in pritiskov vojaške organizacije na družinsko življenje pripadnikov/-ic.

Zadovoljstvo družin omogoča lažje opravljanje obveznosti pripadnika in tudi lažje spoprijemanje vojaške družine s številnimi stresnimi dejavniki, kot so odsotnosti ali zdravstvene težave pripadnika.

\section{METODE IN VZOREC}

Raziskavo so izvedli študentje in študentke pri predmetu mirovne operacije (katedra za obramboslovje, Fakulteta za družbene vede, Univerza v Ljubljani), in sicer v lokalnem okolju, iz katerega prihajajo. V vzorec so bile tako zajete družine pripadnikov in pripadnic SV glede na lokalni izvor študentov in študentk. Raziskava temelji na strukturiranih intervjujih, ki so bili prilagojeni glede na okoliščine (partner/-ka, otroci, starši, bratje/sestre).

Opravljenih je bilo 33 intervjujev z družinami pripadnikov in pripadnic. Pripadniki/ice, katerih družinski člani so bili intervjuvani, so bili stari med 21 in 59 let ter so zasedali višje častniške ( 2 moška in 3 ženske), nižje častniške ( 5 moških in 2 ženski), podčastniške (3 moški in 1 ženska) čine ter 17 vojakov. Med pripadniki/-icami, katerih družinski člani so bili intervjuvani, je bila večina moških, in sicer 27 , ter 6 žensk, med njimi je bilo 14 poročenih, 8 v zunajzakonski skupnosti, 1 ločen in 10 samskih pripadnikov ter pripadnic. Intervjuvanih je bilo 20 partnerk in 1 partner, pripadnikov/-ic SV, 15 otrok in 20 staršev, od tega 12 mam in 8 očetov. Vsi pripadniki in pripadnice, katerih družinski člani so bili intervjuvani, so se udeležili najmanj ene MOM.

Intervju je bil sestavljen iz petih sklopov, in sicer vprašanja za pripadnika/-co, partnerja/-ko, otroke in starše, ter iz demografskega sklopa. Z vprašanji za pripadnike/-ce in partnerje/-ke smo preverjali: 1) občutek identifikacije z vojaško organizacijo in podpora partnerja/-ke; 2) težave z usklajevanjem plačanega dela in zasebnega življenja zaradi specifične narave dela v vojaški organizaciji; 3) poznavanje organizacijske in institucionalne podpore, ki ju nudi SV pripadnikom/-cam ter celotnim družinam; 4) usklajevanje plačanega dela in zasebnega življenja med opravljanjem nalog na MOM; 5) vir podpore družinam med opravljanjem nalog v MOM; 6) ponovna vzpostavitev odnosov v družini po vrnitvi z MOM. Sklop vprašanj za otroke je bil prilagojen njihovi starosti, obsegal pa je: 1) poznavanje poklica starša, ki je zaposlen v SV; 2) odnosi v družini med MOM in sprejemanje odsotnosti enega od staršev; 3) (vojaška vs. civilna) socialna mreža otrok; 4) odnos do poklica in službe starša, ki je zaposlen v SV. Sklop vprašanj za starše je obsegal te vsebine: 1) viri podpore staršem v času otrokove napotitve $v$ MOM; 2) odnos do otrokove napotitve v MOM. 


\section{RAZISKOVALNI VPRAŠANJ}

Teoretično izhodišče omenjenega članka je koncept pohlepnih institucij, kar predstavljata družina in vojaška organizacija, ter koncept usklajevanja med plačanim delom in zasebnim življenjem. Pri tem so posameznikom na voljo različne vrste podpore in v članku se osredotočamo na tri: socialno, institucionalno ter organizacijsko. Izhajajoč iz uvodoma opredeljenih ciljev, smo postavili raziskovalni vprašanji: 1) V kolikšni meri vojaške družine razumevajo SV kot pohlepno organizacijo, ki otežuje usklajevanje družine in plačanega dela; 2) Katera vrsta podpore je med vojaškimi družinami najbolj zaželena in katera najbolj izkoriščena.

\section{ANALIZA}

\subsection{Organizacijska podpora}

Nekaj več kot polovica partnerjev/-k pripadnikov SV meni, da narava vojaške organizacije od pripadnikov zahteva, da SV postavljajo na prvo mesto, torej pred družino. Prav tako je med partnerji/-kami pripadnikov deljeno mnenje, ko gre za vprašanje fleksibilnosti dela v vojaški organizaciji. Malo manj kot polovica partnerjev/-k meni, da vojaška organizacija pripadnikom omogoča dovolj dopusta, bolniške odsotnosti itn., medtem ko druga polovica vprašanih meni, da je partnerju/-ki zaposlenega/-e v SV težje uveljavljati na primer bolniško za varstvo bolnega otroka. Težavne so tudi pogoste odsotnosti zaradi dežurstev, kar je sicer bolj prisotno le v nekaterih enotah. Prav tako se kot ovira velikokrat pojavlja oddaljenost od delovnega mesta in s tem povezana vožnja, zaradi katere je pripadnik/-ca odsotna veliko več kot 8 ur. Pripadniki/-ce v takšnem primeru praktično ne sodelujejo pri organizaciji družinskega življenja in izvajanju obveznosti (nakupi, vožnja otrok v vrtec ali šolo, skrb za popoldanske dejavnosti otrok).

Višji častniki menijo, da SV enako obravnava tako matere kot očete z majhnimi otroki, vendar pa z zakonom predpisane ugodnosti pogosteje uveljavljajo ženske. Drugi intervjuvanci (podčastniki in vojaki) pa so izrazili občutek, da imajo ženske z majhnimi otroki več ugodnosti kot moški. Mnenje intervjuvanih pripadnic glede ugodnosti za starše z majhnimi otroki je deljeno, pri čemer je le približno polovica pripadnic zadovoljnih.

Na splošno pa prevladuje mnenje, da je SV pri zagotavljanju različnih ugodnosti močno omejena z zakonodajo in da bi morali biti izvzeti iz javnega sektorja.

Nekateri partnerji/-ke so izrazili nezadovoljstvo z zdravniško oskrbo svojega družinskega člana na MOM. Prav tako so izrazili nezadovoljstvo s prevozom vojakov v nekatere MOM in domov ter $\mathrm{z}$ organizacijo dopusta, pa tudi z obveščenostjo SV o položaju pripadnikov/-ic v MOM. Razlik pri odgovorih partnerjev/-ic častnikov/-ic, podčastnikov/-ic in vojakov ni mogoče opaziti. 
Med intervjuvanimi družinami prevladuje občutek, da od SV ne čutijo nobenega pritiska glede pravil vedenja zaradi partnerjeve-/kine (starševe, otrokove) zaposlitve v SV. Pripadniki/-ce sicer priznavajo, da obstajajo pravila, ki v nekaterih pogledih vplivajo na njihovo vedenje v prostem času, vendar zato ne čutijo večje obremenitve oziroma pritiska.

\subsection{Institucionalna podpora}

Družine so med seboj zelo razdeljene glede mnenj o institucionalni podpori, ki jim jo zagotavlja SV. Tretjina vprašanih meni, da SV omogoča dovolj institucionalne podpore pripadniku/-ci in njegovi družini. Ob tem pa je pomembna ugotovitev, da večina teh družin pomoči SV v času MOM ni potrebovala oziroma je ni uporabila. Preostali dve tretjini sta opozorili na pomanjkanje tovrstne podpore. Mnenje lahko povzamemo z izjavo pripadnika SV in njegove žene, ki trdita, da povabila na piknike, verske obrede in srečanja niso dovolj. Družinski člani pripadnika/-ce, ki se udeleži MOM, bi potrebovali predvsem tehnično pomoč, kot je na primer varstvo otrok, ali finančno pomoč, kot je na primer subvencioniran vrtec. Mnenja partnerjev/-k pripadnikov/-ic lahko povzamemo z mnenjem ene od partnerk:

»Pomoči SV sama nisem rabila, je pa ta pomoč vse prej kot zadovoljiva. Prave pomoči praktično ni. To, da se oglasijo takrat, ko smo vsi veseli, ne pomeni nič. Dobro bi bilo, da bi bil nekdo v času MOM članom družine (na primer ženi, $k i$ ostane sama) na voljo, če bi kaj potrebovala, tega pa ni. To bi bilo potrebno, da se vojak na MOM ne sekira in razmišlja, kako je doma.« (Intervju 32).

Največ informacij o MOM so družine pridobile od pripadnikov/-ic, nekaj manj iz medijev (internet, televizija), tisti, ki so se udeležili t. i. družinskega dneva, pa tudi tam. Najbolj so se zanesli na informacije, ki so jim jih posredovali pripadniki/-ce. Udeleženke družinskega dneva so dejale, da na tem srečanju zveš predvsem, kako pomembno je delovanje na določeni MOM.

Med intervjuvanimi družinami je bilo mogoče zaznati tudi nezadovoljstvo z obveščanjem družine o razmerah na MOM in o zdravstvenem stanju pripadnikov/-ic na MOM. Če pride do napada na bazo ali lokacijo v bližini baze, so družinski člani prestrašeni in zaskrbljeni, zato bi prav takrat bil potreben hiter in učinkovit sistem obveščanja SV.

Velika večina pripadnikov in pripadnic je prepričana, da so imeli z družinskimi člani dovolj stikov. Ti so jim bili omogočeni predvsem prek telefonskih linij in internetne povezave. Nezadovoljstvo s količino stikov so izpostavili nekateri pripadniki, ki so delovali na MOM UNIFIL Libanon ali zaključen NTM-I Irak. Eden izmed intervjuvanih je sicer izpostavil, kako se je podpora SV na tem področju skozi leta spreminjala:

»Moram reči, da so bili vzponi in padci. Na primer na začetku leta 1999 in 2000 je bilo omogočeno veliko zadev na misiji, potem se je pa zadeva začela zmanjševat do 
neke kritične točke, ki je bila 2005/06, potem se je pa začelo spet neke zadeve urejati in dodajati.« (Intervjuvanec 19).

Družine skupno ugotavljajo, da je bilo včasih manj stikov, njihova pogostost in kakovost pa se dvigata z vsako nadaljnjo MOM.

Le dve družini sta v okviru institucionalne podpore omenili službo za celostno skrb pripadnika, kar govori o slabi obveščenosti družin. Če partnerji potrebujejo pomoč, se prej obrnejo na starše in prijatelje. Nekaj partnerjev pozna sistem pomoči, ki pa se jim ne zdi primeren (pikniki družin, telefonske številke psihologov). Pravijo, da bi potrebovali nekaj bolj osebnega, kot na primer osebni pogovor, s čimer bi SV pokazala, da se zanima za družine pripadnikov/-ic, pa tudi več informacij o pripadnikih od SV, predvsem takrat, kadar so pripadniki na nevarnejših območjih. Zadovoljstvo s skrbjo SV za družine pa je bilo izraženo v Enoti za specialno delovanje, saj tako poveljnik kot tudi sodelavci vzdržujejo redne stike z družinami pripadnikov na MOM.

\subsection{Socialna podpora}

\subsubsection{Mnenje pripadnikov in pripadnic o socialni podpori v času MOM}

Pri vprašanju podpore družine se med vsemi intervjuvanci pojavlja enak vzorec. Velika večina pripadnikov poudarja, da se je o odhodu v MOM treba z družino temeljito pogovoriti. Vzorec je pokazal, da se pri starših in partnerjih/-kah pojavlja strah pred nevarnostjo MOM, da pa negativne posledice nemalokrat odtehta finančna stran. Če je pripadnik/-ca v MOM napoten/-a po ukazu, je nasprotovanje družinskih članov še toliko večje. Pripadniki/-ce, ki so s partnerko/-jem že več let, so v odgovorih navadno poudarili, da se o odhodu na misijo partnerja vedno odločata skupaj.

Otroci večine intervjuvancev so bili v času misije še zelo majhni, zato njihovega nasprotovanja niso občutili. Kritično obdobje za otroka je po mnenju intervjuvanih družin med tretjim in petim letom starosti. Intervjuvanci pa so enotnega mnenja, da je tako pri majhnih kot tudi pri tistih nekoliko starejših otrocih pomemben predvsem pogovor. Če je odsotnost pripadnika/-ce nekoliko daljša (na primer enoletna), se pri otrocih lahko pojavi bolj odklonilen odnos do naslednjih MOM in bolj zaščitniški ter posesiven odnos do enega od staršev.

Priprave pred odhodom pripadnika/-ce v krogu družine navadno potekajo $\mathrm{s}$ pogovorom. Velika večina pripadnikov je poudarila, da so svoje družinske člane na odhod pripravljali predvsem tako, da so jim pojasnili vse okoliščine, podrobnosti in potek dela na misiji. So pa moški pripadniki izpostavili, da je bilo družine treba pripraviti tudi v bolj tehničnem smislu. Partnerkam so na primer priskrbeli vse potrebne dokumentne in stike, jih naučili zamenjati avtomobilsko pnevmatiko, pripraviti kurjavo, če so na misijo odhajali v zimskih mesecih, itn. Pripadnice svojih partnerjev v tehničnem smislu niso pripravljale, vsaj tako lahko sklepamo iz njihovih odgovorov, se pa pojavi primer najema varuške med odsotnostjo pripadnice. 
Odnosi znotraj večine družin se, po besedah pripadnikov/-ic, niso spremenili. Dobršen del intervjuvanih pripadnikov meni, da se je njihov odnos s partnerko po vrnitvi še poglobil, predvsem se je povečalo medsebojno zaupanje, hkrati pa priznavajo, da je marsikdaj prihajalo tudi do konfliktov.

»V̌̌asih je prišlo do konfliktov zaradi odsotnosti, praznine, ker človeka nisi mogel videt vživo, ga objeti.« (Intervju 28).

Zaradi dolgotrajne odsotnosti pripadnikov/-ic pride tudi do ločitev, kar sicer ne moremo posplošiti na večino, vendar pa takšni primeri dokazujejo, da lahko daljša odsotnost enega izmed partnerjev negativno vpliva na zvezo.

Velika večina vprašanih pripadnikov/-ic se je pri vrnitvi z misije srečevala vsaj z manjšimi težavami pri ponovnem vzpostavljanju družinske dinamike. Nekateri so potrebovali le nekaj dni ali tednov, drugi celo več mesecev. Za oteženo privajanje na domače okolje sta kriva predvsem stres ob menjavi okolja in navajenost na drugačen način življenja. Mnenje enega izmed intervjuvancev:

"Velika težava je bil stres. Ko se enkrat vrneš z misije, nobena stvar ni več ista." (Intervju 28).

Velika razlika pri vrnitvi iz MOM se pokaže med spoloma. Ženske so namreč izpostavile, da jim v MOM ni bilo treba skrbeti za gospodinjska dela, kar je omogočalo popolno predanost plačanemu delu. Ponovno opravljanje gospodinjskih opravil so ob vrnitvi nazaj razumele kot veliko breme.

\subsubsection{Mnenje partnerjev/-k o socialni podpori med MOM}

Partnerji/-ke dojemajo odsotnost pripadnika/-ce zaradi napotitve v MOM kot del vojaške službe. Odsotnost sprejmejo, a to ne pomeni, da so partnerji/-ke zadovoljni/-e. Predvsem partnerke kot precejšnjo pomanjkljivost dolgotrajne odsotnosti občutijo odsotnost pri pomembnih dogodkih, kot so rojstni dnevi, maturantski plesi, prvi šolski dan, poroka otroka idr. Kot težja preizkušnja za partnerje/-ke pa je bila izpostavljena dolgotrajna odsotnost v obdobju, ko so otroci še majhni. Takrat se vsa odgovornost preloži na ramena tistega od staršev, ki ostane doma, kar je izrazila pripadnica SV, ki je hkrati tudi partnerka:

»Preden je šel, se je zdelo brezupno. V trenutku, ko so se na Brniku zaprla vrata za njim, je bilo vse enostavno, pa ne zato, ker bi pričakovala, da bo dejansko enostavno, sploh ne, ampak zaradi tega, ker si postavljen v situacijo in vě̌, da moraš to sprejeti. Stisneš zobe in gre. Jaz vedno pravim, da ni na misiji tisti, ki gre, ampakje na misiji tisti, ki ostane doma.« (Intervju 20).

Partnerke, ki so prav tako zaposlene v SV, sprejemajo poklic svojega moža in ga razumejo, saj, kot poudarijo, same vedo, kako vojska deluje. Tudi one se na odsotnost prilagodijo, vendar hkrati dodajajo, da se na življenje brez partnerja ne 
moreš popolnoma prilagoditi. Najmanj težav s prilagoditvijo dolgotrajnih odsotnosti je bilo zaznanih med pari, ki nimajo otrok.

Okolica se do družine, v kateri sta oče ali mama pripadnika SV, ne vede drugače. Partnerji/-ke pripadnikov opažajo, da širše okolje med napotitvijo v MOM izraža večji interes tako za počutje odsotnega pripadnika/-ce kot tudi za značilnosti MOM (podnebje, delovni pogoji, bivalne razmere, nevarnost itn.). Kadar je pripadnik/-ca odsoten/-a, partnerjem-/kam pomagajo in jih podpirajo predvsem njihovi starši ter nekoliko manj tudi starši odsotnega pripadnika/-ce. Intervjuji so pokazali, da so velikokrat v veliko pomoč prijatelji. Pomoč je potrebna predvsem pri varstvu otrok in fizičnih opravilih, pa tudi za psihično oporo ter spodbudo. V skupnostih brez otrok partnerji ne potrebujejo pomoči, vendar pravijo, da če bi jo potrebovali, bi jo verjetno tudi dobili. V dveh primerih pa družina kljub izraženi potrebi, pomoči od širšega socialnega okolja ni dobila.

Pripadnica, ki se je prav tako kot partner udeležila MOM, pravi, da je zelo pomemben časovni razmik med MOM in da je z napredovanji lažje usklajevanje družine in službe. Sama ima rada svojo službo, medtem ko partnerstvo, v katerem sta oba partnerja hkrati tudi pripadnika SV, vidi kot izziv.

\subsubsection{Mnenje otrok o socialni podpori v času MOM}

Iz raziskave je jasno razvidno, da otrokom primarno socialno podporo dajejo starši oziroma ožja družina. Otroci se po podporo največ obračajo k staršu, ki ostane z njimi. Mlajši otroci podporo iščejo le pri družini, medtem ko najstniki oporo najdejo tudi pri prijateljih, s katerimi se po odsotnosti starša več družijo. Skoraj vsi otroci imajo vsaj enega prijatelja, ki je v podobni situaciji in ima vsaj enega starša zaposlenega v SV. Le eden od vprašanih otrok je prijatelje, ki imajo starše, zaposlene v SV, spoznal prek organiziranih neformalnih srečanj SV. Od okolice pa ne pričakujejo podpore, saj večina niti ne želi razglašati, da je eden izmed staršev zaposlen v vojski, zato jih širša okolica ne obravnava nič drugače kot druge otroke.

Nekatere partnerke so pri mlajših, predšolskih otrocih opazile vedenjske spremembe, in sicer so otroci več jokali, se odtujili od odsotnega starša, niso vedeli, kako ravnati ob njegovi vrnitvi ipd. Partnerji/-ke so potožili, da bi jim pomoč partnerja prišla prav predvsem v času pubertete otrok. Ko so otroci starejši, vedenjskih sprememb zaradi odsotnosti enega od staršev ni opaziti. Partnerji/-ke so izpostavili pomembnost stikov s pripadnikom/-co, predvsem prek Skypa, in pogost pogovor o odsotnem staršu, s čimer je misel nanj kljub fizični odsotnosti v družini v resnici vedno prisotna.

\subsubsection{Mnenje staršev o socialni podpori v času MOM}

Starši pripadnikov SV, ki so odšli v MOM, prav tako kot preostali člani družine (partner/-ka, otroci) med odsotnostjo potrebujejo socialno oporo. Vsi vprašani imajo $\mathrm{v}$ bližini sorodnike in prijatelje, na katere se lahko obrnejo. Primarno podporo jim predstavljajo družinski člani, večinoma partner/-ka, ki ostane doma, in se vzajemno 
čustveno podpirajo med pripadnikovo/-čino odsotnostjo. Očetje so enoglasno odgovarjali, da socialne podpore niso potrebovali in si je niti ne želijo, medtem ko so matere podporo potrebovale in iskale pri bližnjih sorodnikih, prijateljih ter sosedih. Večini mater je veliko pomenilo že to, da je kdo povprašal o njihovem otroku, saj so potrebovale pogovor ter nekoga, s komer so lahko delile svoje skrbi. Za nekatere posameznice pa so bili pogovori in vprašanja okolice breme, saj so jih nenehno opominjali, da je njihov otrok v MOM.

Sklep Pogovori s slovenskimi vojaškimi družinami so pokazali, da je v Sloveniji prevladujoča oblika podpore socialna podpora. Že Godina $(1990 ; 2009)$ govori o tradiciji kolektivistične kulture (tudi Hofstede, 2001), ki je tradicionalno pretežno agrarnim družbam omogočala preživetje z močno povezanostjo družine in širšega socialnega okolja. Tudi slovenske vojaške družine se med odsotnostjo družinskega člana največkrat po pomoč obrnejo na primarno socialno okolje, medtem ko je institucionalna opora šele druga izbira. Slednje bi si sicer želeli več, vendar je na podlagi odgovorov težko oblikovati enotno mnenje glede njene oblike. Intervjuvane družine so izrazile željo po pomoči pri varstvu otrok, psihološki pomoči oziroma potrebo po pogovoru, tehnični pomoči, predvsem pa so poudarili potrebo po boljši obveščenosti o tem, kaj se dogaja v MOM.

Opažamo razdvojenost pripadnikov/-ic in njihovih družin, ki bi si po eni strani želele več pozornosti SV med trajanjem MOM, in priznanje, da so družine med odsotnostjo v težkem položaju, vendar pa hkrati ne želijo dopustiti, da se SV preveč vpleta v njihovo zasebno življenje. Treba bi bilo torej najti pravo razmerje med pomočjo vojaške organizacije in vdorom v zasebnost pripadnikov/-ic ter njihovih družin. ${ }^{3}$ Se pa kot zelo pomemben segment institucionalne podpore kaže obveščanje družin v času napotitve na MOM. Posebno takrat, kadar je pripadnik/-ica dlje časa nedosegljiv/-a prek elektronskih medijev (Skype, Facebook ipd.) ali prek telefona, so družinski člani zaskrbljeni. Slednje se intenzivira v primeru medijskega poročanja o napadu na ožjem območju (v bližini baze) delovanja pripadnikov/-ic. Dobro bi bilo vzpostaviti sistem hitrega obveščanja družinskih članov, prek katerega bi SV lahko reagirala $\mathrm{v}$ omenjenih situacijah.

Domala soglasno je bilo izraženo zadovoljstvo z zagotavljanjem dostopa do interneta v MOM ter posledično omogočanje pogostih stikov z družinskimi člani. To se je kot posebnega pomena pokazalo predvsem $\mathrm{v}$ družinah $\mathrm{z}$ majhnimi otroki, saj pogosti pogovori z odsotnim staršem, pri čemer ga lahko tudi vidijo, praviloma olajšajo težave, ki nastopijo ob dolgotrajni odsotnosti (jok, odtujenost, trma idr.).

Stališča o organizacijski podpori so v vojaških družinah deljena. Del družin je zadovoljen, medtem ko približno polovica izraža določeno stopnjo nezadovoljstva s fleksibilnostjo delovnega časa partnerja/-ke, zaposlenega/-e v SV (na primer bolniška odsotnost med otrokovo boleznijo), ki naj bi bila manjša kot pri partnerju/-ki, ki

3 Kot primer dobre prakse se pokaže Enota za specialno delovanje, SV. 
ni zaposlen/-a v SV. To kaže, da pomemben del vojaških družin ne zaznava večjih sprememb v organizacijski podpori v zadnjih sedmih letih, saj sta podobno ugotovili že Černič Istenič in Kneževič Hočevar (2006). Avtorici ugotavljata, da imajo pripadniki/-ce SV manj možnosti za dogovarjanje o premakljivem delovnem času, o koriščenju dopusta ali možnosti zamenjave delovnega mesta zaradi potreb družine (Černič Istenič in Kneževič Hočevar, 2006, str. 233). Tako se kot ena izmed težav pri usklajevanju zasebnega življenja in plačanega dela v nekaterih primerih izpostavlja oddaljenost delovnega mesta, kar pripadniku/-ci domala onemogoča aktivno sodelovanje v družinskem življenju skozi delovni teden (vožnja otrok na obšolske aktivnosti, v vrtec, nakupi idr.).

Za zdaj glavni vir opore pripadnikom/-cam SV ostaja partner/-ka, slednjim pa širša družina. Če govorimo, da slovenska družba postaja vedno bolj individualizirana ter so družine vedno bolj nuklearnega tipa, se ob dolgotrajni odsotnosti v MOM praviloma kot koristnejši izkaže razširjeni tip družine, z vsemi sorodniki in morda tudi prijatelji. Močno podporo partnerjev/-k pripadnikov/-ic SV lahko delno interpretiramo tudi v kontekstu ugotovitev Černič Istenič in Kneževič Hočevar (2006), ki izpostavljata močno povezanost med delovnim in družinskim okoljem v vojaški organizaciji in pomembno vlogo partnerja/-ke v življenju vojaka.

Partnerja se večinoma strinjata, da je udeležba v MOM pozitivno vplivala na njun odnos. Zveze so po njihovih besedah postale bolj trdne, povečalo se je medsebojno zaupanje. Hkrati med partnerkami prevladuje mnenje, da je udeležba v MOM vplivala na pripadnikovo osebnost. Večina partnerk je opazila pozitivne spremembe; pripadniki naj bi postali bolj odgovorni, čuteči, prilagodljivi in zrelejši. Analiza je pokazala na nekatere razlike med spoloma, in sicer pri ponovnem prevzemanju vloge v družini po vrnitvi iz MOM. Ženske so soglasno poudarile, da jim je ponovna delitev časa in energije med plačano delo ter gospodinjska opravila pomenila veliko težavo. To nakazuje, da so tudi pripadnice vojaške organizacije še vedno glavne nosilke gospodinjstva in so tako veliko bolj izpostavljene zahtevam dveh pohlepnih institucij kot moški kolegi. Slednja ugotovitev pojasnjuje, zakaj so dosedanje raziskave pokazale zelo nizko stopnjo pohlepnosti SV in konflikta med družino in vojsko med anketiranci so bili večinoma moški.

Glede na uvodoma zastavljene cilje in raziskovalni vprašanji lahko ugotovimo, da kljub visoki stopnji podpore vojaškemu načinu življenja med partnerji/-kami pripadnikov/-ic SV, partnerji/-ke vendarle občutijo pohlepnost vojaške organizacije, ki jo dojemajo kot postavljanje službe pred družino. To občutijo predvsem, ko je treba poskrbeti za bolne otroke, pri fleksibilnosti koriščenja dopusta ali bolniške odsotnosti ipd. Ugotavljamo, da družine največ koristijo socialno podporo, pri čemer pa si vsaj polovica vprašanih želi tudi več institucionalne podpore, ki naj bi potekala v teh oblikah: 1) obveščanje družin o stanju v MOM; 2) osebni stiki (pogovori) z družinami; 3) tehnična pomoč; 4) pomoč pri varstvu otrok. 
Kakovostna in učinkovita organizacijska, institucionalna in socialna opora zagotavljajo primerno podporo pripadniku/-ci ter njegovi/njeni družini, kar omogoča učinkovito in varno opravljanje službenih obveznosti. Uravnotežena kombinacija vseh treh podpor pa se kaže v zadovoljstvu pripadnikov/-ic in njihovih družin.

\section{Literatura}

1. Blanchard, E. Samantha, 2012. Are the Needs of Single Parents Serving in the Air Force Being Met? Advances in Social Work 13-1, str. 83-97.

2. Bowen, G. L. in Orthner, D. K., 1989. The Organization Family: Work and Family Linkages in the US Military. New York: Praeger Publishing.

3. Coser, A. Lewis, 1974. Greedy Institutions: Patterns Of Undivided Commitment. New York: Free Press.

4. Crompton, Rosemary, 2006. Employment and the Family: The Reconfiguration of Work and Family Life in Contemporary Societies. Cambridge: Cambridge University Press.

5. Černič Istenič, M. in Kneževič Hočevar, D, 2006. Usklajevanja dela in družine v Slovenski vojski. Sodobni vojaški izziv. 4, str. 215-236.

6. Eisenberger, R., Huntington R., Hutchison S., Sowa, D., 1986. Perceived organizational support. J Appl Psychol. 71, str. 500-507.

7. Dremelj, P., 2003. Sorodstvene vezi kot vir socialne opore posameznikov. Družboslovne razprave. 43, str. $149-170$.

8. Godina Vuk, V., 1990. Vpliv kulturnih vzorcev in tradicije na procese družbenega razvoja. Družboslovne razprave. 7-10, str. 179-86. http://www.druzboslovnerazprave.org/medial pdf/clanki/dr10Godina.PDF, 15. 6. 2011.

9. Godina Vuk, V., 2009. Intervju. Mladina. 5, 10. 7. 2009.

10. Heilmann, G. Sharon, Bell, John E., McDonald, Gavin K.. 2009. Work--Home Conflict : A Study of the Effects of Role Conflict on Military Officer Turnover Intention. Journal of Leadership \& Organizational Studies. 16-1, str. 85-96.

11. Hofstede, Geert, 2001. Culture's Consequences: Comparing Values, Behaviors, Institutions and Organizations across Nations. London in New Delhi: Sage Publications.

12. Intervju 19: Intervju z družino pripadnika/ce Slovenske vojske. Opravljen oktobral novembra 2012.

13. Intervju 20: Intervju z družino pripadnika/ce Slovenske vojske. Opravljen oktobral novembra 2012.

14. Intervju 28: Intervju z družino pripadnika/ce Slovenske vojske. Opravljen oktobral novembra 2012.

15. Intervju 32: Intervju z družino pripadnika/ce Slovenske vojske. Opravljen oktobral novembra 2012.

16. Juvan, J. in Jelušič, L., 2007. Vojaške družine na stičišču zahtev med družino in vojaško organizacijo. Teorija in praksa. 44-5, str. 551-67.

17. Kanjuo Mrčela, A., 2007. Uvod: Plačano delo in ostalo. V Kanjuo Mrčela A., Černigoj Sadar N., (ur.) Delo in družina - s partnerstvom do družini prijaznega delovnega okolja. Ljubljana, FDV, 2007, str. 11-22.

18. Kogovšek, T., Hlebec, V., Dremelj, P. in Ferligoj, A., 2003. Omrežja socialne opore Ljubljančanov. Družboslovne razprave. 43, str. 183-204.

19. Lapierre, L. M., Spector, P. E., Allen, T.D , Poelmans, S., Cooper, C.L., O'Driscoll, M. P. in ostali, 2008. Family-supportive organization perceptions, multiple dimensions of workfamily conflict, and employee satisfaction: A test of a model across five samples. Preprint online. 
20. MacDermid Wadsworth in Shelley Southwell, Kenona, 2011. Families: Extreme Work and Extreme "Work-Family". The ANNALS of the American Academy of Political and Social Science. 638, str. 163-183.

21. Martin, A. James in McClure, Peggy, 2000. Today's Active Duty Military Family: The Evolving Challenges of Military Family Life. V J. A. Martin, L. N. Rosen in L. R. Sparacino, ur. The Military Family: A Practice Guidef or Human Service Providers. Preager Publishers, 2000, str. 3-25.

22. Moelker, Rene in Van der Kloet, Irene, 2003. Military Families and the Armed Forces: A Two-Sided Affair? V G. Caforio, ur. Handbook Of The Sociology Of The Military. New York: Springer, 2003, str. 201-223.

23. Orthner, D. K., Bowen, G. L., Varga, G. B., 1990. The Organization Family: A Question of Work and Family Boundaries. Marriage \& Family Review. 15-3, str. 15-36.

24. Rhoades L., Eisenberger, R., 2002. Perceived organizational support: a review of the literature. J Appl Psychol. 87, str. 698-714.

25. Sachau, Daniel A., Gertz, Jessica, Matsch, Mahlia, Johnson Palmer, Ashley, Englert, David, 2012. Work-Life Conflict and Organizational Support in a Military Law Enforcement Agency. Journal of Police and Criminal Psychology. 27-1, str. 63-72.

26. Segal, Mady W, 1986. The Military and The Family as Greedy Institutions. Armed Forces and Society. 13-1, str. 9-38.

27. Soeters, L. Joseph, Winslow, J. Donna in Weibull, Alise, 2003. Military Culture. V G. Caforio, ur. Handbook of the Sociology of the Military. New York: Springer, 2003, str. 237-249.

28. SOMF - Strenghtening Our Military Families, 2011. Meeting America's Commitment. Washington: White House.

29. Vuga, J., Juvan, J., 2011. Vloga posameznikovega primarnega socialnega okolja v odnosu do vojaške organizacije: primer Slovenske vojske. Družboslovne razprave. 66-5, str. 89-109.

30. Whyte, E. H., 1956. The Organization Man. New York: Simon and Schuster.

31. Zakon o delovnih razmerjih (ZDR-1). Ur. l. RS 21/2013 (13. 3. 2013). http://www.uradnilist.si/1/content?id=112301, 27. 4. 2013).

32. Zakon o službi v Slovenski vojski (ZSSloV). Ur. l. RS 68/2007 (30. 7. 2007).http://www. uradni-list.si/1/objava.jsp? urlid=200768\&stevilka=3761, 27. 4. 2013. 